RAC, Rio de Janeiro, v. 22, n. 6, novembro/dezembro, 2018

\title{
Editorial:
}

\section{Mudanças em 2018 e Expectativas para 2019}

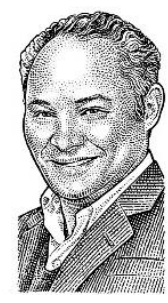

Wesley Mendes-Da-Silva

https://orcid.org/0000-0002-5500-4872

Fundação Getulio Vargas, Escola de Administração de Empresas de São Paulo, São Paulo, SP, Brasil

Neste editorial do último número do volume relativo a 2018, é mister o registro de um conjunto de avanços alcançados pela Revista de Administração Contemporânea (RAC), bem como o agradecimento às pessoas e instituições que colaboram para o cumprimento do papel desempenhado pela RAC este ano. A RAC é, indubitavelmente, um dos principais meios de interlocução da comunidade acadêmica da área de negócios, seja entre pesquisadores interessados nesse campo de conhecimento, ou mesmo entre a comunidade acadêmica e outros segmentos da sociedade. Por isso, enfatizou-se neste ano um conjunto de esforços no sentido de estreitar a distância entre a RAC do seu principal alvo: autores e leitores, sem esquecer da contribuição do revisor anônimo, sem a qual as revistas científicas teriam dificuldades em conduzir o processo editorial, ao menos nos moldes atuais (Mendes-Da-Silva, 2018a).

Esse esforço induziu, em 2018, a adoção de um rol de iniciativas por parte desta editoria, entre essas podem ser destacadas: (a) o estímulo ao maior uso de mídias sociais por parte de autores; (b) a inclusão da evidenciação de diferentes métricas de altmetria (PlumX e Altmetrics) dos trabalhos publicados pela RAC; (C) a produção de um novo website para a RAC, com novas funcionalidades, no sentido de tornar transparentes as políticas adotadas pela revista (Mendes-Da-Silva, 2018b); (d) a promoção de publicação de materiais adicionais acerca dos procedimentos adotados pelos autores no desenvolvimento das pesquisas publicadas pela RAC, em linha com práticas internacionais, conforme recomenda o Committee on Publication Ethics (COPE, 2016, 2018), destacando-se que a declaração de ética e boas práticas é um requisito obrigatório e, dificilmente, um periódico é indexado sem ele. A RAC trata esse assunto como algo essencial, e espera que, especialmente, os autores sigam os altos padrões adotados por esta revista; (e) o maior detalhamento e a atualização das políticas editorias adotadas pela RAC, de modo a permitir melhor interlocução com os agentes indexadores, bem como orientar, de forma mais adequada possível, o grande público de interessados na RAC; (f) a atualização e a maior diversificação da equipe editorial, de modo a permitir e estimular a diversificação e o crescimento da qualidade dos trabalhos publicados pela RAC, além de contribuir para a diversificação de periódicos que têm citado trabalhos publicados por essa revista. 
Essas iniciativas são decorrentes do entendimento de que o aumento do rigor da seleção de trabalhos é pedra angular para o aumento do padrão de qualidade da ciência que é feita no campo de negócios no âmbito brasileiro. Espero que, em 2019, seja viável a continuidade de esforços na mesma direção e no mesmo sentido de consolidar o posicionamento da RAC. Estamos empenhados em preparar a revista para alcançar os indexadores dos quais a RAC ainda não participa, como forma de aumentar a presença desta revista na literatura de alta qualidade na área de negócios (Marques, 2018).

Um dos aspectos mais importantes acerca da relevância de um periódico é o reconhecimento por parte de pesquisadores. Isto se reflete nas métricas de visibilidade conquistada que, ao menos em parte, é medida por meio de citações recebidas de periódicos indexados. Entende-se que, à medida que um periódico acumula artigos publicados, o número de citações deva ser maior. Ainda a respeito da consolidação de um periódico, nota-se como desejável a diversificação do conjunto de originadores de citações. No caso particular da RAC, a Figura 1 apresenta a evolução do número de citações recebidas em periódicos indexados na Scopus, desde a criação da RAC em 1997 até 2017 (período no qual recebeu ao menos 550 citações, conforme plataforma Scopus), e também a distribuição de citações recebidas por parte de trabalhos publicados pela RAC, considerando-se periódicos indexados no Scielo. Ao observar a evolução das citações à RAC na Scopus, nota-se que, entre 2004 e 2010, o volume de citações parece ter sido mais expressivo. Já quando consideramos as citações no Scielo, constata-se que a RAC parece estar alcançando mais intensamente periódicos editados no Brasil.

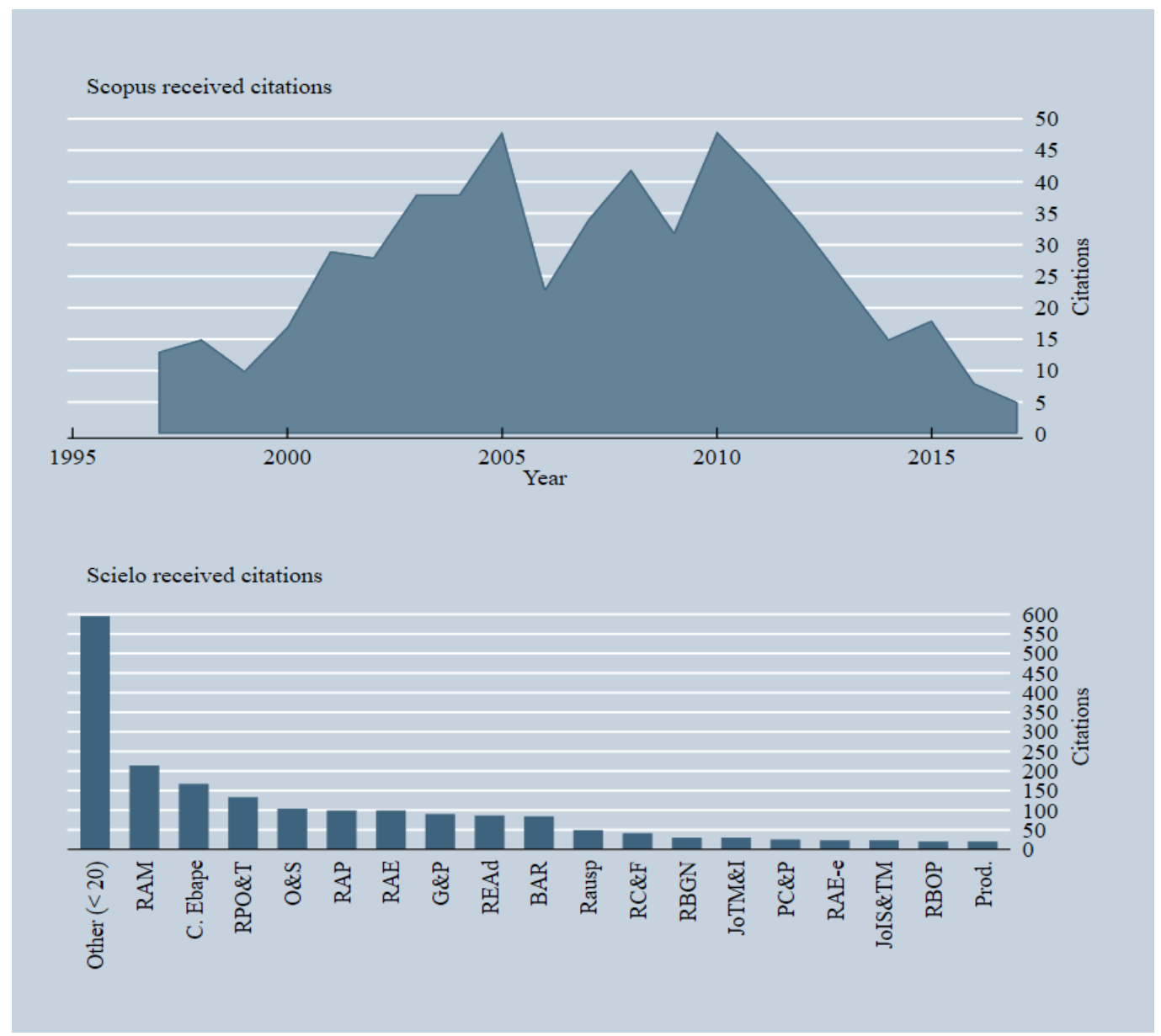

Figura 1. Citações Recebidas pela RAC de Periódicos Indexados na Scopus e no Scielo (1997-2017) Esta figura, recuperada de http://doi.org/10.5281/zenodo.1490499, apresenta a evolução do número de citações recebidas pela RAC entre os periódicos indexados na Scopus e na Scielo. As consultas foram realizadas nas plataformas em 15/11/2018. Foi usada a função de pesquisa avançada na Scopus REFSRCTITLE, com o título do periódico entre aspas. Em adição, buscou-se filtrar as formas variantes do título da RAC. Na Scopus (porção superior da figura) foram encontradas 559 citações a trabalhos publicados pela RAC entre 1997 e 2017. Já no Scielo foram encontradas 1.932 citações concedidas por outros periódicos (porção inferior da figura). Fonte: Elaborado pelo autor a partir de dados das plataformas Scopus e Scielo. 
Por esse motivo, a editoria da RAC tem buscado adotar estratégias que atenuem essa concentração, mesmo que a linha editorial da RAC seja centrada em aspectos mais relevantes para o Brasil e demais mercados emergentes. Um exemplo de estratégia orientada ao alcance de maior diversificação das citações é a publicação de edições especiais (lideradas por pesquisadores reconhecidos no Brasil e no ambiente internacional) focadas em temas explicitamente prioritários e relevantes para a sociedade brasileira (e outras economias emergentes). Esperamos ter, em 2019, a publicação de duas edições especiais dedicadas a dois temas que entendemos sejam caracterizados por elevado potencial de impacto na sociedade: gestão e tecnologia na região amazônica, e governança de empresas familiares.

Novos tempos apresentam-se, novos esforços de pesquisa são necessários em diversas áreas, e em negócios não é diferente (Guerras-Martín et al., 2014). É indubitável a relevância de tecnologias emergentes, tais como Blockchain e Internet of Things para a pesquisa em negócios, especialmente pelo potencial de induzir aumentos de produtividade (Lo \& Campos, 2018; Mendes-Da-Silva, 2019). Convém realçar que pesquisas suportadas por tecnologias emergentes têm o potencial de contribuir tanto em termos de métodos, ou mesmo como tema de pesquisa per se, versando acerca do impacto das tecnologias emergentes sobre os temas relevantes na pesquisa em negócios. É notória a evolução do volume de dados disponíveis e, por extensão, também é notória a carência de estudos caracterizados pelo exame de dados tão ricos quanto a oferta desses apresenta-se para o futuro próximo (Cullen, 2017; Iliho \& Saritha, 2019). É possível que esta constatação seja decorrente da carência de pesquisadores detentores de habilidades que permitam a produção de conhecimento a partir de data driven research (Kimmons \& Veletsianos, 2018).

Ao final deste ano que ora se encerra, cabe registrar o reconhecimento e o agradecimento às agências de fomento que têm contribuído com o financiamento parcial da manutenção das atividades da RAC, notadamente CNPq e Capes; aos revisores anônimos (para conhecer a lista de pessoas que têm desempenhado esse papel recomenda-se ver as nominatas de revisores, regularmente disponíveis em bases anuais no website da RAC) sem os quais esta revista não cumpriria seu papel, conforme destaquei no editorial do número anterior da RAC (Mendes-Da-Silva, 2018a); aos editores associados e demais membros da governança da RAC, os quais têm desempenhado papel chave na atração e na seleção de trabalhos para a revista; ao Prof Editor Herbert Kimura, pelo trabalho anteriormente desenvolvido de forma exemplar na editoria da RAC; aos colaboradores e fornecedores da Anpad que têm servido à RAC; à Presidência da Anpad e sua Diretoria de Publicações, pelo irrestrito apoio na condução da editoria deste periódico. E, finalmente, registro meu sincero e honesto agradecimento aos autores e aos leitores da RAC, motivo de existência desta revista, que se dedica a disseminar conhecimento de acesso aberto e irrestrito na área de negócios.

\section{Palavras finais}

Nesta edição da RAC publicamos seis artigos inéditos e um caso para ensino. Dois dos seis artigos são oriundos de instituições sediadas na região Sul do Brasil. Primeiro, Hilka Pelizza Vier Machado, que atua em Santa Catarina, contribuiu com o artigo intitulado Crescimento de Empresas na Perspectiva de Pequenos Empreendedores de Base Tecnológica. Com esse trabalho, a autora busca compreender o processo do crescimento de empresas de base tecnológica, na perspectiva de empreendedores, focando determinantes e dificuldades de crescimento. A autora defende que os principais resultados alcançados esmiúçam a importância de percepções do empreendedor na compreensão do processo de crescimento, enquanto fenômeno multidimensional.

O segundo artigo é um ensaio teórico que vem do Paraná, de autoria de Francis Kanashiro Meneghetti, intitulado Organizações Totalitárias: Modus Operandi e Fundamentos. Conforme afirma a autoria, esse trabalho decorre de reflexões ocorridas ao longo de dez anos de estudos realizados a partir da análise histórica das seguintes organizações: os Einsatzgruppen, o complexo de Auschwitz, e os campos de extermínio da Operação Reinhard - Sobibór, Belzec e Treblinka, que compuseram o Estado Nazista; as organizações terroristas Al-Qaeda e Estado Islâmico, com presença em diversos países por meio de redes de células cooperativas. 
O terceiro artigo inédito desta edição, Antecedentes e Consequências da Participação de Advisor em Fusões e Aquisições, é de autoria de Marcelo Daniel Araújo Ermel e de Roy Martelanc, que atuam na Universidade de São Paulo. Nesse trabalho, os autores intencionaram investigar o papel da presença de advisors no tempo de negociação e na taxa de sucesso das transações. Além disso, identifica características das transações que sejam determinantes para a participação de advisors. Os autores desse artigo apontam que os principais resultados obtidos indicam que as transações, as quais contam com a participação de advisors, são caracterizadas por maior tempo de transação, tradicionalmente associado ao papel ativo dos advisors, além de maior taxa de sucesso.

O quarto artigo é de autoria de Pedro Cavalcante, atuante no Instituto de Pesquisas Econômicas Aplicadas (IPEA), é intitulado Innovations in the Federal Government During the Post-new Public Management Era. Nesse artigo, o autor busca analisar se as inovações no governo federal seguem as tendências internacionais da administração pública, especialmente na Era pós Nova Gestão Pública (NGP). O autor realiza análise de conteúdo para verificar essas relações com base nas iniciativas finalistas do Prêmio Federal de Inovação de Gestão Pública (PFIGP) de 2007 a 2015. Os principais resultados sugerem que a maioria delas possuem ao menos um princípio/diretriz do pós-NGP, sendo as relações mais recorrentes: colaboração/parceria; coordenação/controle e participação/engajamento, tendo sido encontradas diferenças pouco expressivas entre finalistas e vencedores desse prêmio.

Romulo Benites de Souza Luciano, do Instituto Brasileiro de Mercado de Capitais (Ibmec), contribuiu com o artigo cujo título é Aplicação da Smart Contract nos Contratos de Gás Natural: Uma Análise Exploratória. Nesse trabalho, o autor busca apresentar uma das tecnologias emergentes que podem transformar o ambiente de negócios ao redor do mundo, o Smart Contract (SC), como proposta para automação da gestão de contratos no processo de comercialização do gás natural, em linha com tendências de aumento expressivo do uso de tecnologias na gestão das empresas.

O sexto e último artigo inédito vem de Pernambuco, Organizational Creativity Management: Discussion Elements, e é de autoria de Henrique Muzzio e de Fernando Gomes Paiva Júnior. Nesse artigo, os dois autores intencionam trabalhar com o conceito teórico de gestão da criatividade, concebido como a gestão do indivíduo criativo, da liderança criativa e da cultura criativa. Os autores concentramse na criatividade como um precursor da inovação e avaliam-na como capaz de melhorar a competitividade organizacional, haja vista a premissa de que a criatividade possa ser entendida como um fenômeno social. Os autores propõem-se a abordar condições e características relacionadas ao indivíduo, à liderança e à cultura. Encerra esta última edição de 2018, o Caso para Ensino que vem de Minas Gerais intitulado Dilema Orçamentário: A Busca pela Estabilidade no Contexto de Retração, cuja autoria é de Camila Henriques de Paula, Wânia Candida Silva, Magnus Luiz Emmendoerfer e de Luiz Antonio Abrantes.

A editoria da Revista de Administração Contemporânea, nesta oportunidade, deseja um excelente 2019 ao seu público! Que tenham todos uma leitura proveitosa e inspiradora desta edição!

Indicadores do Processo Editorial da RAC (janela móvel julho/2017 a junho/2018)

\begin{tabular}{llll}
\hline Situação & Jul'17-Jun'18 & Jun'17-Mai'18 & Mai'17-Abr'18 \\
\hline Total de artigos publicados & 36 & 35 & 42 \\
Total de artigos submetidos & 422 & 440 & 319 \\
Artigos em avaliação & 52 & 56 & 55 \\
Artigos aceitos e publicados & 12 & 26 & 18 \\
Artigos aceitos a serem publicados & 12 & 06 & 04 \\
Tempo médio entre submissão e publicação (\# dias) & 237 & 298 & 315 \\
\hline
\end{tabular}




\section{Referências}

Committee on Publication Ethics. (2016). Data sharing. Retrieved October 20, 2018, from https://publicationethics.org/files/u661/Notes\%20from\%20Forum\%20Discussion\%20Topic_12 _February\%202016_DATA_SHARING_final.pdf

Committee on Publication Ethics. (2018). Principles of transparency and best practice in scholarly publishing. $\quad$ Retrieved $\quad$ October 15, 2018, from https://publicationethics.org/files/Principles_of_Transparency_and_Best_Practice_in_Scholarly _Publishingv3_0.pdf

Cullen, J. G. (2017). Educating business students about sustainability: A bibliometric review of current trends and research needs. Journal of Business Ethics, 145(2), 429-439. https://doi.org/10.1007/s10551-015-2838-3

Guerras-Martín, L. A., Madhok, A., Montoro-Sánchez, A. (2014). The evolution of strategic management research: Recent trends and current directions. Business Research Quarterly, 14(2), 69-76. https://doi.org/10.1016/j.brq.2014.03.001

Iliho, \& Saritha, S. K. (2019). Community detection methods in social network analysis. Advances in Intelligent Systems and Computing, 813, 849-858.

Kimmons, R., \& Veletsianos, G. (2018). Public internet data mining methods in instructional design, educational technology, and online learning research. Tech Trends, 62(5), 492-500. https://doi.org/10.1007/s11528-018-0307-4

Lo, F.-Y., Campos, N. (2018). Blending internet-of-things (IoT) solutions into relationship marketing strategies. Technological Forecasting and Social Change, 137, 10-18. https://doi.org/10.1016/j.techfore.2018.09.029

Marques, F. (2018). Táticas para elevar o impacto. FAPESP Pesquisa, (263), 46-49. Recuperado de $\mathrm{http} / / /$ revistapesquisa.fapesp.br/2018/01/16/taticas-para-elevar-o-impacto/

Mendes-Da-Silva, W. (Ed.). (2018a). Editorial: Reconhecimento da contribuição do revisor anônimo. Revista de Administração Contemporânea, 22(5). Recuperado de https://rac.anpad.org.br/index.php/rac/article/view/1291/pdf. $\quad$ https://doi.org/10.1590/19827849rac2018180281

Mendes-Da-Silva, W. (Ed.). (2018b). Editorial: Promoção de transparência e impacto da pesquisa em negócios-editorial. Revista de Administração Contemporânea, 22(4). Recuperado de http://www.scielo.br/scielo.php?script=sci_arttext\&pid=S141565552018000400639\&lng=pt\&tlng=pt. https://doi.org/10.1590/1982-7849rac2018180210

Mendes-Da-Silva, W. (2019). Individual behaviors and technologies for financial innovations. New York: Sage. https://doi.org/10.1007/978-3-319-91911-9

\section{Autor}

Wesley Mendes-Da-Silva

Rua Itapeva, 474, $8^{\circ}$ andar, 01332-000, São Paulo, SP, Brasil.

E-mail: rac.wesley.mendes@gmail.com 